\title{
Los comienzos de un arquitecto. Crónica del viaje dle Sáenz de Oíza por Estados Unidos y México
}

\author{
An architect's beginning. Chronicle of Sáenz de Oíza's trip \\ through the United States and Mexico
}

Resuimen

María del Pilar Salazar Lozano* psalazarl@unav.es

Pablo Rodríguez Rodríguez*** p.rguez.r@gmail.com Zaida García-Requejo $* * *$ zaida.garcia@udc.es

*Universidad de Navarra **Investigador independiente *** Universidade da Coruña

Recibido: 30/Sep/2021 Aceptado: 16/Dic/2021

\section{F}

rancisco Javier Sáenz de Oíza fue un pionero en España en su tiempo. Su desarrollo como arquitecto y su docencia quedaron marcados por un viaje que le llevó a recorrer Estados Unidos durante casi un año. En 1948, poco después de haber obtenido el título, ganó la beca Conde de Cartagena, lo que le permitió formarse en un país poco conocido por la mayoría de sus compatriotas. Gracias al hallazgo de las cartas que mensualmente remitía a la Academia de Bellas Artes de San Fernando, se ha podido reconstruir su viaje paso a paso, los lugares visitados, los contactos realizados, sus temas de investigación, las dificultades que se encontró. De esta manera se puede entender la huella que le dejó este viaje, lo cual permite obtener enseñanzas para sacar el máximo rendimiento a los viajes que siguen realizando los profesionales de la arquitectura por el mundo entero.

Palabras clave: viaje; Estados Unidos; Francisco Javier Sáenz de Oíza; experiencias vitales; intercambio cultural

\section{Abstract:}

Francisco Javier Sáenz de Oíza was a pioneer in Spain in his time. His development as an architect and his teachings were marked by a trip that took him to the United States for almost a year. In 1948, shortly after obtaining his degree, he won the Conde de Cartagena scholarship, which allowed him to be trained in a country little known for most of his compatriots at that time. Thanks to the discovery of the letters that he sent monthly to the San Fernando Academy of Fine Arts, it has been possible to reconstruct his trip step by step, the places he visited, the contacts he made, his research topics, and the encountered difficulties. In this way, it is possible to understand its mark, which allows us to obtain lessons to get the most out of the trips that architecture professionals continue to make around the world.

Keywords: trip; The United States; Francisco Javier Sáenz de Oíza; life experiences; cultural exchange 


\section{Introducción y métodos}

Recorrí Estados Unidos para aprender cómo vivía la gente... al volver de Estados Unidos conocía cómo funcionaba el tráfico... Allí aprendí a entender que resolver el sistema de tráfico era hacer que no se fundieran los cables eléctricos... la solución a un problema plantea otros problemas (...) En América descubrí que el arte moderno me interesaba menos que la tecnología moderna. Los semáforos y las zapatas de hormigón americanas... te das cuenta lo que es el espíritu americano, inventivo por todos los lados, la oficina de patentes allí es tan importante como el Museo del Prado aquí (Alberdi y Sáenz Guerra, 1996, p. 19).

Francisco Javier Sáenz de Oíza recorrió en 1948 los Estados Unidos, viaje que le marcó notablemente, como se puede ver tanto en la docencia que desarrolló a su vuelta a España, como en su obra proyectada y construida. Este viaje es de sobra conocido (Martín Gómez, 2006), pero siempre lo ha sido mediante fuentes secundarias, a través de los testimonios de personas cercanas al arquitecto, o entresacando información de sus conversaciones y escasas veces que él lo menciona (Sáenz de Oíza, 1993).

La novedad que planteamos en este artículo es el poder contar con las cartas que mensualmente debía hacer llegar a la fundación Conde de Cartagena desde los Estados Unidos para justificar la beca recibida. En ellas va narrando cronológicamente los viajes realizados, los puntos que más le llaman la atención, las materias de estudio a las que se dedica y los contactos que establece. Esta colección de cartas no ha sido publicada y no ha sido utilizada por investigadores en otras publicaciones. Ahora, contado en primera persona por Sáenz de Oíza, podemos desentrañar cada uno de sus pasos en el continente americano.

César Martín ha explicado cuáles fueron las consecuencias inmediatas de ese viaje, por lo que en este artículo nos vamos a centrar en el viaje en sí mismo, en conocerlo y de esa manera intentar extraer enseñanzas que nos sirvan para los innumerables viajes que hoy en día realizamos los arquitectos y los que se organizan desde nuestras Escuelas de Arquitectura.

El interés de esas cartas recaba en ser una fuente escrita por el mismo autor, en el momento de la vivencia, más allá de una reflexión posterior o de datos parciales obtenidos a través de diversas fuentes. Algunas de las suposiciones reflejadas por los autores previos acerca de este viaje se confirman como ciertas y otras se desmienten. Otras aparecen como novedosas, como es el paso del arquitecto por México. Es por ello por lo que añadir un nuevo estudio sobre este viaje. Quedaban suficientes incógnitas abiertas acerca de uno de los viajes más comentados de esa época como para merecer el esfuerzo de recabar toda la información disponible y darle cauce, exponerla de manera que pueda ser fuente de información para otros estudiosos posteriores, de forma que posean datos ciertos de cuáles fueron las intenciones de Oíza y cuáles fueron cada uno de sus pasos en el continente americano.

Esta investigación se engloba dentro de un proyecto acerca de la influencia que han tenido los viajes en el recorrido profesional de los arquitectos, llevado a cabo por la Escuela de Arquitectura de la Universidad de Navarra. Dicho proyecto ha ido dando sus frutos en la última década, tanto en la organización del congreso "Viajes en la transición de la arquitectura española hacia la modernidad" (Pozo y García-Diego, 2010), como en la publicación del libro Architect's journey:building, travelling, thinking (Buckley y Rhee, 2011); y desde entonces, y de una manera más espaciada, en diversos artículos y publicaciones.

Por otro lado, hace apenas unos años, en 2018, se cumplió el centenario del nacimiento del arquitecto Francisco Javier Sáenz de Oíza, lo que originó una serie de exposiciones, publicaciones y revisiones de su trayectoria como arquitecto y como docente. Consideramos que es ahora, con esa perspectiva ya histórica de su obra y de la época que le tocó vivir, cuando se puede analizar y sacar conclusiones, poniéndolas en contexto, de cómo llegó a ser el arquitecto que conocemos.

Solo nos queda indicar, antes de comenzar con la exposición de este artículo, que en las citas se ha mantenido el término "América" o "americano" para designar a los Estados Unidos, ya que Sáenz de Oíza así lo hacía al hablar o al escribir sobre su experiencia, aunque únicamente se estaba refiriendo a este país y a México, los dos estados americanos que recorrió durante esta estancia.

\section{Viajes a EEUU de arquitectos españoles}

Al igual que durante siglos-desde su descubrimientovarios arquitectos españoles siguieron el recorrido hacia el oeste que tantos europeos habían realizado con afán descubridor, pero esta vez no era un nuevo mundo lo que buscaban, sino principalmente una nueva tecnología. Los arquitectos que se desplazaron a Estados Unidos lo hacían atraídos por el canto de sirenas que les había llegado por publicaciones, por el contacto con arquitectos americanos o por el testimonio de anteriores viajeros.

Desde principio del siglo $\mathrm{XX}$, arquitectos españoles realizaron viajes a Estados Unidos con diferentes finalidades. Viajes que les marcaron en sus trayectorias posteriores y que transmitieron a través de diversos medios, algunos de los cuales han llegado hasta nosotros. Unos dejaron muchos testimonios y otros ninguno: tal y como relata Bustos Juez (2015), Pedro Muguruza no dejó nada escrito sobre el viaje que realizó como consultor en varios proyectos residenciales de Nueva York y Florida; a diferencia de Roberto Fernández Balbuena, que escribió 
"Los rascacielos norteamericanos" en 1922 (Fernández Balbuena, 1922). José Moreno Villa hizo lo mismo en 1927, en "Cartas de Nueva York" (Moreno Villa, 1927a) y "Retales de Nueva York" (Moreno Villa, 1927b); y Luis Moya realizó varias series de dibujos sobre su experiencia americana (García-Gutiérrez Mosteiro, 1993).

Modesto López Otero formó parte de una Comisión Técnica que recorrió, en 1928, varias universidades de Norteamérica para conocer sus instalaciones y poder luego proyectar la Ciudad Universitaria de Madrid. También formaron parte de esa expedición Manuel Sánchez Arcas, Rafael Bergamín, Miguel de Los Santos y Mariano Gómez Ulla. Este viaje de dos meses de duración fue financiado por la Fundación Rockefeller.

Más cercanos en el tiempo a Saénz de Oíza fueron Gabriel Alomar, que realizó estudios del Master in City and Regional Planning, en el Massachusetts Institute of Technology en 1945, o Eduardo Garay, que era el arquitecto jefe del servicio de arquitectura del Instituto Nacional de Previsión.

El director del Instituto le encargó en 1945, junto a los jefes médicos y de ingeniería, un viaje específico para el estudio de los principales hospitales de Estados Unidos. Antonio Cámara Niño fue becado durante tres meses por la Junta de Relaciones Culturales, entre 1947 y 1948, para realizar estudios en la University of Columbia, en Nueva York.

En los años 50 se fueron normalizando los viajes y aumentando las becas que se concedían desde diferentes instituciones. Después de los Pactos de Madrid de 1953, las relaciones y conexiones con los Estados Unidos se facilitaron, ya que había un interés por ambas partes: los españoles buscaban el desarrollo técnico, y económico del país y los americanos querían mantener los pactos, generando una buena imagen, además de demostrar lo que podían ofrecer en los campos más avanzados.

A Sáenz de Oíza le siguió, como pensionado de la beca Conde de Cartagena tres años más tarde, Fernando Chueca Goitia, que viajó a Estados Unidos desde mayo de 1951 hasta abril de 1952, realizando estudios de urbanismo y sociología en la Universidad de Columbia, además de visitar diferentes ciudades y archivos. Rafae de la Hoz, en 1955, consiguió también una beca para hacer un programa de verano para estudiantes internacionales en el MIT (Massachusetts Institute of Technology). Diez años más tarde que Oíza, en 1958, fue Valentín Picatoste quien obtuvo una beca Eisenhower para una estancia de diez meses en Estados Unidos. Ese mismo año viajaron a los Estados Unidos Mariano Marín y Desiderio Pernas, con dos de las primeras becas Fullbright para arquitectos. Como se ve, Oíza fue un pionero, abriendo camino a los muchos que venían detrás, hasta llegar a un momento en el que estos viajes perdieron su novedad y se fueron normalizando.

Si nos detenemos a analizar la relevancia de los viajes en la obra de dichos arquitectos o en la arquitectura española en general, nos adentramos en un Mediterráneo de difícil abarque, del que nos atreveremos a dar algunas pinceladas. España vivía en los finales de los años 40 un momento de aislamiento, además de pobreza. Los contactos con el exterior eran escasos, las noticias sobre la arquitectura que llegaban desde el extranjero apenas existían. Los materiales de que disponía el campo de la construcción eran los acostumbrados, por lo que se podían realizar pocos alardes estructurales y se tendía a recuperar las formas tradicionales. En cuanto al urbanismo, la problemática respecto a las cuestiones de tráfico era casi inexistente, aunque sí tenía relevancia para el crecimiento de las ciudades. A los arquitectos españoles les llegaban noticias parciales de "nuevas formas", de un "lenguaje internacional" que solo conocían a través de fotografías.

Es por ello por lo que cada uno de los viajes que realizaron estos arquitectos fuera de España supuso una bocanada de aire fresco. Significó conocer nuevas posibilidades alejadas de la realidad española del momento, y por lo menos les abrió la cabeza a un futuro que otros países ya estaban viviendo, en uno u otro aspecto. Volvían con nuevos métodos de construcción, con un renovado interés en la tecnología, en el desarrollo de los nuevos materiales, con nuevas metodologías de organización de los estudios y las constructoras, con contactos con grandes arquitectos modernos, con nuevas formas y con reflexiones sobre los porqués que había detrás de esas nuevas formas.

En esa época la carrera de arquitectura era de muy difícil acceso y más difícil finalización. Los arquitectos formaban parte de la élite intelectual de España. Por ello, cada uno de esos viajes tuvo una gran huella. Eran enormemente aprovechados, después de una intensa preparación.

Este es el marco en el que se engloba el viaje que vamos a narrar.

\section{La beca}

El Conde de Cartagena dejó a su muerte, en 1929, su legado a las Reales Academias Española, de la Historia, de Bellas Artes de San Fernando, de Ciencias Exactas, Físicas y Naturales, Nacional de Medicina y al Patronato del Museo Nacional del Prado (Real Academia de Ciencias Exactas, Físicas y Naturales, 2009). Las Academias destinaron el importe del legado tanto a la concesión de becas como a diversos fines de investigación, premios, etc.

La real Academia de Bellas Artes de San Fernando, patrono de la "Fundación Conde de Cartagena", convocaba las becas dentro de su ámbito, estipulando cada año el número de las mismas, a qué disciplina se concedían (pintura, escultura, música o arquitectura) y en qué país se iba a desarrollar: Inglaterra o Estados Unidos.

Según recogen las actas de las reuniones de la Comisión de Arquitectura de la real Academia de Bellas Artes de San Fernando del 10 de octubre de 1947, se presentaron dos candidatos a la beca Conde Cartagena en la categoría de Arquitectura: Francisco Javier Sáenz de Oíza y Manuel Rieses Fernández, ganándola el primero. A sus 28 años, Sáenz de Oíza ya había sido becado anteriormente por la Academia, con el premio Carmen del Río (Figura 1). 


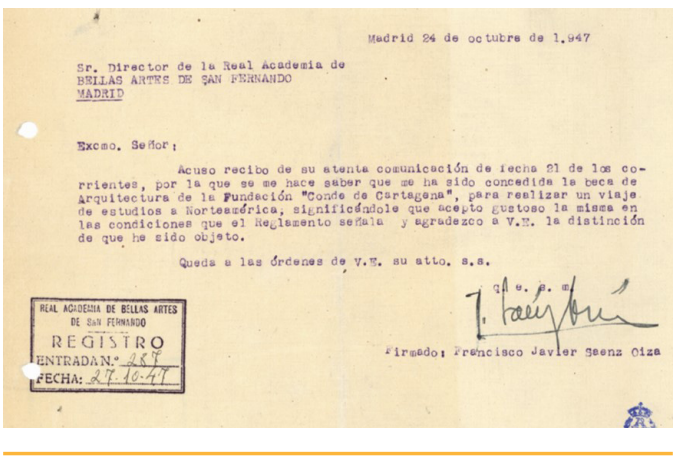

Figura 1: Carta de aceptación de la beca Conde de Cartagena. 24 de octubre 1947

Fuente: Archivo Biblioteca. 5-221-1. Real Academia de Bellas Artes de San Fernando

Se le comunicó la concesión de la beca el 21 de octubre de 1947, siendo su salida hacia los Estados Unidos el 21 de febrero de 1948. Como parte de sus obligaciones durante la estancia debía enviar una carta mensualmente a la Academia, en la que debía dar noticias de sus trabajos, estudios y proyectos. A su vuelta, debía entregar la memoria y obra realizadas durante su estancia. Es gracias a estas cartas remitidas mensualmente como podemos tener acceso a información hasta ahora desconocida.

\section{El viaje por EEUU}

El arquitecto pisa los Estados Unidos por primera vez en la ciudad nevada de Nueva York, donde vuela después de una escala en Londres, alargada sin planificar debido a las condiciones meteorológicas. Modesto López Otero, quien había recorrido 20 años antes las mejores universidades norteamericanas, le había recomendado estudiar "el empleo de nuevas formas y materiales y los perfeccionamientos en los servicios e instalaciones complementarias de los edificios" (Sáenz de Oíza, 1948), a lo que intenta ceñirse durante su estancia. Igualmente, le había recomendado visitar los grandes centros urbanos y hacerse con un gran número de publicaciones que pudiera estudiar a la vuelta.

Es por ello que durante las primeras semanas en Nueva York visita asiduamente la Biblioteca Central de Nueva York y también la de la Universidad de Columbia. All recorre algunos de los principales edificios, tales como The American Museum of Natural History, The Central Park Zoo, The Frick Collection, el Empire State, The Hyde Planetarium, The Metropolitan Museum of Art, The Rockefeller Center, the Museum of Modern Art, entre otros. Le llama la atención, en el campo del urbanismo, cómo se produce el acceso a Manhattan desde diferentes vías, tanto de automóviles como ferroviarias. Resalta también la visita a la Universidad de Columbia y su Escuela de Arquitectura, impresiones sobre las que volveremos más adelante (Figura 2).

Al comienzo de su estancia, allí se suceden las cartas con la Real Academia en las que habla de su necesidad económica y de la imposibilidad de viajar, adquirir publicaciones y vivir de manera adecuada a su condición de arquitecto con el importe que la beca le proporciona:

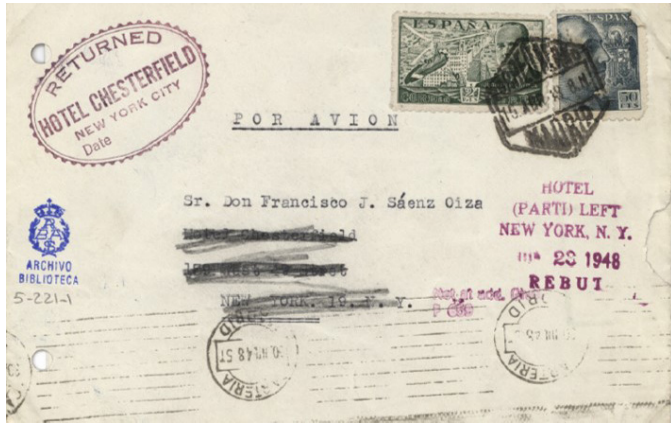

Figura 2: Carta dirigida a Francisco Javier Saénz de Oíza, con domicilio en Nueva York

Fuente: Archivo Biblioteca. 5-221-1. Real Academia de Bellas Artes de San Fernando

se ha encontrado con el elevado precio de la vida en los Estados Unidos. Plantea como soluciones la posibilidad de reducir el tiempo de estancia, de dividirla entre Estados Unidos y México, o de solicitar dinero a su familia. La Real Academia le permite reducir a seis meses su estancia con el mismo importe económico, pero lo que finalmente hace Sáenz de Oíza es solicitar dinero a un familiar que se encuentra en Norteamérica y permanece incluso más tiempo de los ocho meses inicialmente planteados. Son nueve meses en total los que está en el continente americano, desde el 24 de febrero de 1948 al 20 de noviembre, como puede verse en la Figura 3 y la Figura 4.

A las pocas semanas de llegar se traslada a Washington por varias razones, principalmente para seguir un curso intensivo de inglés que sigue durante dos meses y que le ofrecen como pensionado, ya que al tener un escaso conocimiento del idioma le resulta difícil la comunicación. Allí resalta su visita al recién acabado edificio de la National Gallery of Art, señalando "el grado de perfección logrado en el acabado de sus elementos y su sistema de iluminación" (Sáenz de Oíza, 1948). También le resulta de gran interés la posibilidad que se le abre de visitar el Stadtler Hotel y de estudiar sus instalaciones, ya que era uno de los más recientes y mejores hoteles de los EEUU.

Simultanea el estudio del idioma con la asidua visita a las bibliotecas. Fruto de la adquisición de conocimientos técnicos, va tomando notas de los edificios que le gustaría visitar en la ciudad, labor a la que se dedica durante el mes de junio. Visita notables ejemplos de vivienda urbana de la ciudad de Washington. Lamenta la imposibilidad de visitar vivienda en construcción y observar el montaje de las instalaciones, algo para lo que solicitó permiso en diferentes ocasiones, pero que le fue denegado hasta las últimas semanas de su estancia, por lo que tuvo que limitarse a estudiar las obras una vez finalizadas.

En Washington dedica especial atención a las instalaciones de los edificios que visita, tanto de aire acondicionado, como instalaciones sanitarias, de agua, gas, evacuación de basuras, incendios, etc. Buscaba en los libros la información teórica mínima necesaria para aprovechar las posteriores visitas. 


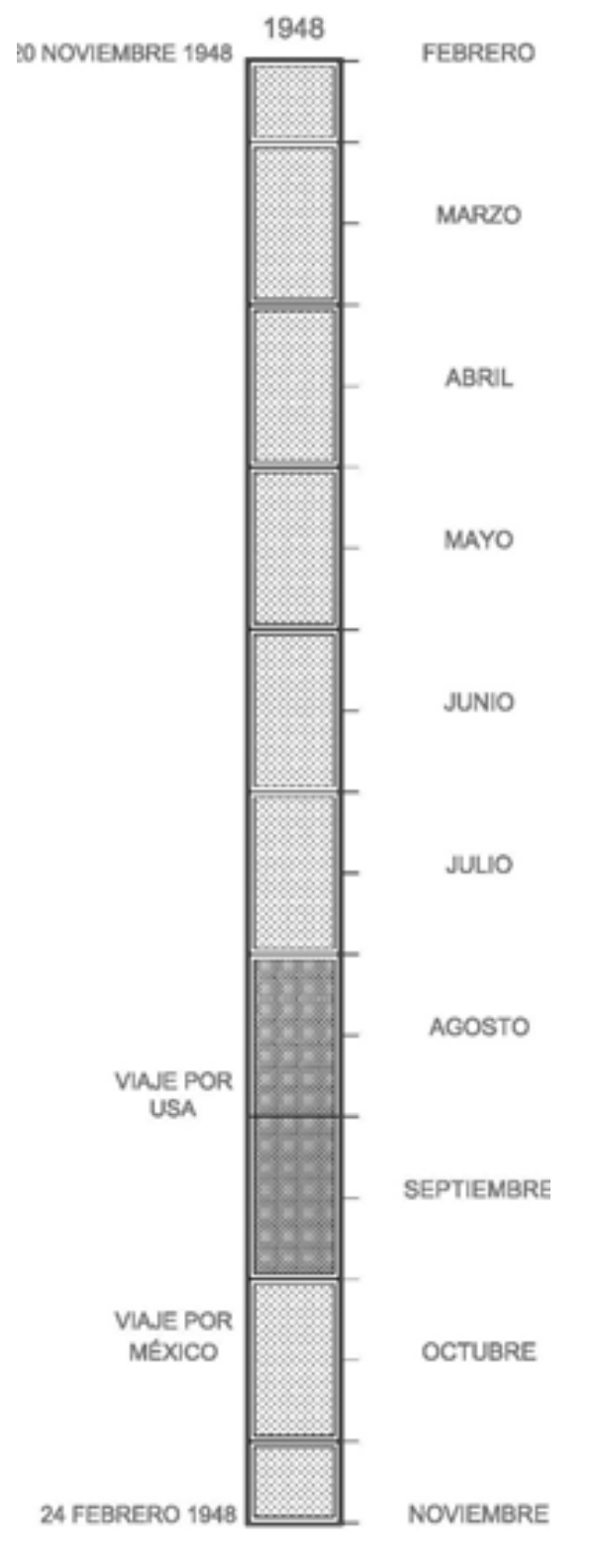

Figura 3: Esquema de la estancia de Sáenz de Oíza en Estados Unidos

Fuente: Elaboración propia

Son tres los temas que tiene en su cabeza y que guían sus visitas en general durante su estancia en el país americano: la ya mencionada cuestión de las instalaciones, el problema urbanístico de la vivienda y los problemas derivados del tráfico (estacionamiento, accesos, medios de transporte públicos, etc.). Estos dos últimos temas son constantes en los estudios que realizan los arquitectos españoles cuando van a los Estados Unidos, dos aspectos que les fascinaban y a los que dedica su atención desde múltiples puntos de vista. Como ya hemos visto, arquitectos como Fernando Chueca Goitia, Gabriel Alomar, José Subirana o Valentín Picatoste, fueron con la idea de estudiar las grandes intervenciones en vivienda o los problemas de comunicaciones. Los Estados Unidos iban por delante en las soluciones a dos problemáticas que, de momento, no se habían planteado en España.

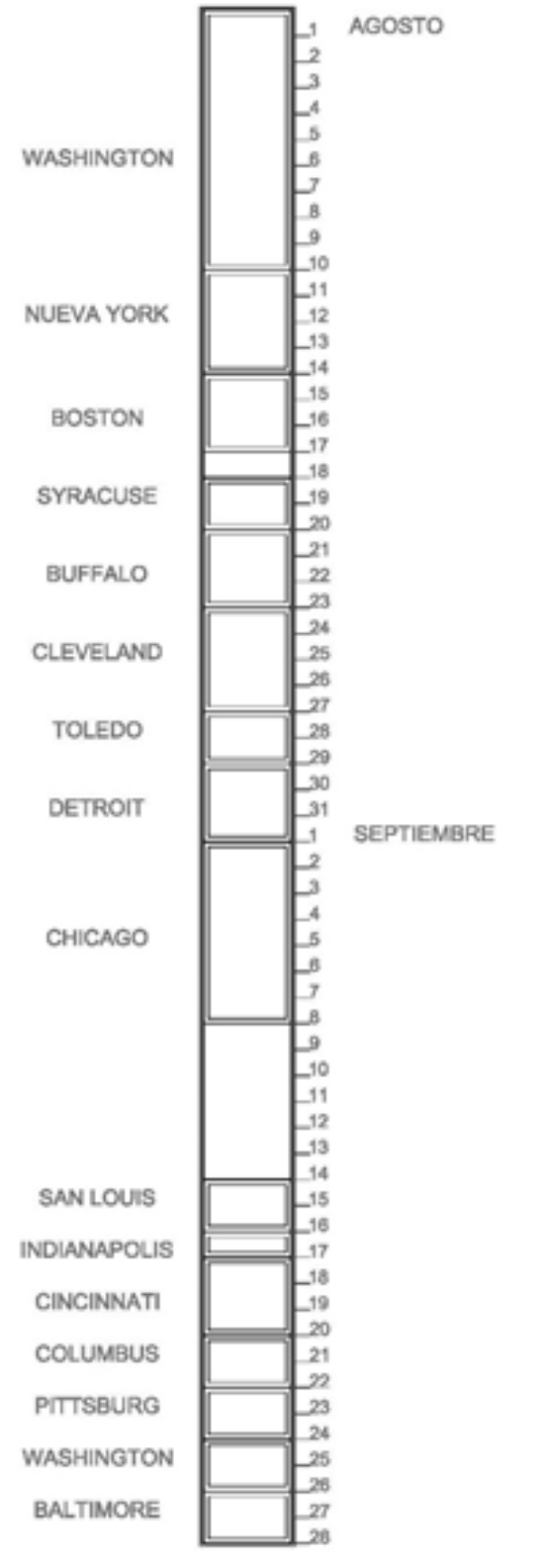

Figura 4: Relación de ciudades visitadas por Sáenz de Oíza durante su estancia en los Estados Unidos en los meses de agosto y septiembre de 1948

Fuente: Elaboración propia

Durante estos meses en Washington establece una red de contactos que le permita realizar de manera fructífera su periplo por otras ciudades. Mantiene una entrevista con el director del Departamento de Educación e Investigación del American Institute of Architects (AIA), que le da cartas de presentación para los diversos miembros de la propia AIA y para las Escuelas de Arquitectura que desea visitar, así como "una relación de las casas constructoras e instaladoras" (Sáenz de Oíza, 1948) de su interés. También conoce al director de Relaciones Culturales de la Pan American Union. Gracias a ello puede planificar el viaje que realizará en agosto y septiembre, después de la formación, tanto en inglés como en conocimientos teóricos, que ha adquirido durante los meses de primavera y comienzos del verano. 
Con esto vemos que, aunque en alguna ocasión se ha considerado que Sáenz de Oíza estuvo viajando por Estados Unidos todo el tiempo en el que estuvo allí, la realidad se aleja bastante. La amplia mayoría de su estancia en USA la pasó en Washington, dedicando solamente los últimos meses a desplazarse, y lo hizo de una manera breve, parando lo mínimo, utilizando el autobús y disminuyendo de esta forma los gastos. Seguramente, sin la recogida de datos, sin el estudio que precedió a este viaje, hubiera sido imposible la profundidad con la que lo realizó. Como él mismo menciona en la memoria:

Tengo en preparación un viaje por las principales ciudades de la zona atlántica de los EEUU donde pueda estudiar sobre terreno los ejemplos interesantes de viviendas y problemas urbanos derivados del problema del tráfico, de muchos de los cuales tengo ya esquemas y datos de interés.

El viaje lo tengo proyectado hacer en autobús, ya que es el medio más económico, aunque un tanto molesto por las grandes distancias de este país (Sáenz de Oíza, 1948).

Parte de Washington el 10 de agosto hacia Nueva York desde donde se propone empezar la ruta que le llevará a recorrer las ciudades de New Haven, Boston, Albany, Syracusa, Buffalo, Cleveland, Toledo, Detroit, Chicago, Kansas, San Louis, Indiana, Cincinnati, Columbus, Pittsburgh, Baltimore y Philadephia. Podemos ver en la Tabla 1 los edificios que visitó en cada una de estas ciudades.

Como se ve, tenía intereses variados, visitando desde fábricas de materiales y elementos diversos, a conjuntos de viviendas, pasando por Universidades, con sus correspondientes Escuelas de Arquitectura, estaciones de tren, hoteles, museos, edificios emblemáticos, residencias de estudiantes, problemas urbanísticos y de tráfico, ejemplos de los grandes maestros de la arquitectura... En realidad, le interesaba cualquier edificio que mereciera la pena, del que le hubieran hablado o que hubiera conocido en los meses de preparación previos.

\section{Las Escuelas de Arquitectura}

De entre todos los edificios que visitó vamos a prestar atención en esta ocasión a las numerosas escuelas de arquitectura y los comentarios que hizo al respecto

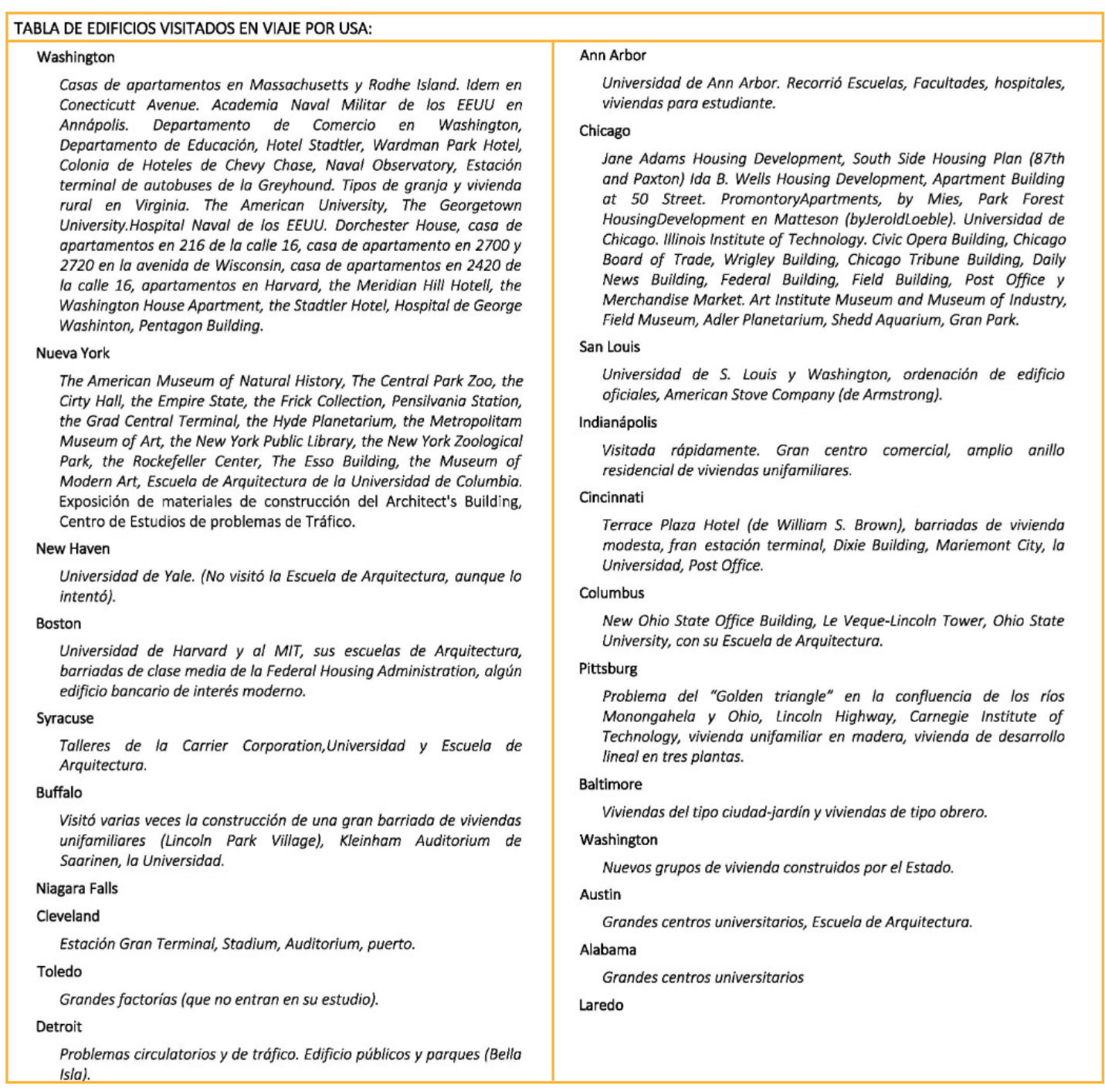


de cada una de ellas. La Escuela de Arquitectura de la Universidad de Columbia es la primera que visita, en las primeras semanas de su estancia en América, recorriendo una exposición de los trabajos más notables, de un carácter moderno al que no estaba acostumbrado, influenciado por Le Corbusier.

Ya en su viaje visita la Escuela de Arquitectura de Harvard, dirigida en ese momento por Walter Gropius, de la que dice "es probablemente la mejor y más interesante de los Estados Unidos" (Sáenz de Oíza, 1948). De la Escuela de Arquitectura del Massachussets Institute of Technology "resalta el aspecto técnico, ya que este centro cuenta con los mejores laboratorios de investigación en los EEUU" (Sáenz de Oíza, 1948). Nombra la Escuela de Arquitectura de Syracusa, pero sin detenerse ni darle mayor importancia. Visitó la Escuela de Arquitectura de la Universidad de Michigan, donde hace algunas interesantes observaciones. En una de sus cartas, narra cómo su director:

le mostró los estudios y trabajos de la Escuela, métodos de enseñanza, etc. La orientación arquitectónica de esta Escuela sigue la corriente americana de los últimos años, difícil de explicar en pocas palabras, pero que opera sobre todo en los primeros años de carrera con formas abstractas e inexpresivas que son difíciles de explicar y cuya lógica es la mayoría de las veces, discutible. Muchas veces ante los trabajos de los alumnos, es posible ver analogías con obras de Picasso por ejemplo. Si Picasso en el terreno de la pintura es discutible, aplicado a las formas arquitectónicas no tiene valor (Sáenz de Oíza, 1948).

Visita también la Escuela de Arquitectura del Illinois Institute of Technology en Chicago. Llama la atención la descripción tan parca que hace de la escuela del IIT, bajo la dirección de Mies: "el Department of Architecture de este Institute desarrolló un trabajo análogo al de otras Escuelas de Arquitectura visitadas, dedicando especial atención al estudio del diseño estructural" (Sáenz de Oíza, 1948). Sin embargo, alaba el proyecto del Campus, realizado por el mismo arquitecto.

En cada ciudad que visita acude a la universidad localizando la escuela de arquitectura. Así, recorre la de Washington, en Saint Louis. Parece que no le sorprende la orientación de ninguna de ellas, sino que lo considera casi como repetitivo: "en la Escuela de Arquitectura de ésta última pude seguir con todo detalle el trabajo a lo largo de los diferentes cursos. La orientación seguida en la misma es como la de otras ya visitadas" (Sáenz de Oíza, 1948). Visita también la Escuela de Arquitectura de la Ohio State University, que considera muy interesante. También, en Austin considera "muy interesante el trabajo de su Escuela de Arquitectura" (Sáenz de Oíza, 1948). Del Carnegie Institute of Technology de Pittsburgh dice, "cuenta con una buena Escuela de Arquitectura de trabajo análogo a los restantes" (Sáenz de Oíza, 1948).

\section{El viaje por México}

Mientras está en Washington, en una escala en medio de su viaje, le presentan al señor Pardo, un ingeniero madrileño que iba a ir de viaje por México durante 10 o 12 días en su propio coche, y quien le ofrece una plaza en el mismo. Después de rápidas gestiones para tramitar su visado, consigue aprovechar la oportunidad que se le ofrece (Figura 5).

Es de gran interés su visita a México, hasta ahora prácticamente desconocida, aunque intuida. Apenas duró dos semanas escasas, pero él mismo afirmó en otra de sus cartas dirigidas a la Academia:

He podido estudiar las orientaciones de la moderna arquitectura en un país que al lado de unas condiciones naturales, históricas, sociales etc. similares a las de nuestra patria, cuenta con la inmediata influencia de los EEUU, donde los progresos de la técnica, la industrialización y la mecanización en todos los órdenes de la vida han llegado a un máximo desarrollo (Sáenz de Oíza, 1948).

Proyecta allí lo que puede llegar a pasar en España, esa mezcla entre una tradición hispana y una cultura moderna. Él mismo piensa que se llegarán a encontrar en España problemas análogos en unos años. Observa y toma notas para reflejarlas en la posterior memoria. Destaca la impresión que le deja la visita a ruinas de las antiguas civilizaciones del lugar y de las monumentales iglesias coloniales que se extienden por todo el país.

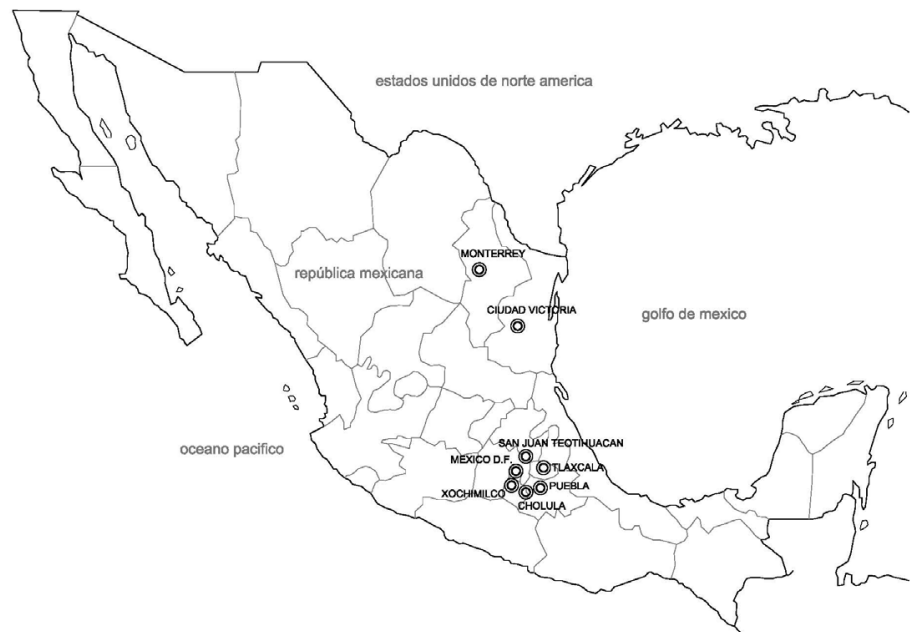


Finaliza su viaje de vuelta en Nueva York, donde todavía le quedan unas semanas antes de regresar a España. Visita un gran número de proyectos de vivienda, siguiendo de cerca el proceso de construcción y montaje de instalaciones, es decir, la parte práctica que antes no había podido adquirir. A la vez, durante esta etapa final, estudia el problema de prefabricación en vivienda, provisional o definitiva, a lo que no había prestado atención hasta ese momento y que considera de enorme interés. La Tabla 2 muestra una relación de los barrios de Nueva York visitados durante su estancia:

También dediqué parte de esta etapa al problema de la prefabricación aplicada a la construcción de grupos de viviendas provisionales o definitivas, que completan mis conocimientos del problema, estudiado en gran parte en Washington a la vista de los construidos en dicha ciudad en periodo de guerra y los edificios construidos por la Tennessee Valley Association, que tuve ocasión de visitar cuando regresaba de mi viaje a Méjico (Sáenz de Oíza, 1948).

\section{La memoria}

Parte del compromiso que contrajo con la Real Academia de Bellas Artes consistía en la entrega de una memoria, en el plazo de seis meses a la vuelta del viaje, en la que reflejara los frutos resultantes del mismo. Sáenz de Oíza tenía una visión particular de sus palabras.

Probablemente la memoria o trabajo final sería más valiosa y podría profundizar más en los temas si me concretara expresamente a una sola materia, pero creo que para mi formación es fundamental una visión completa de todos los problemas de aplicación a nuestra arquitectura (Sáenz de Oíza, 1948).
Según recogen varias cartas intercambiadas con la Academia, hasta mediados de 1952 no entregó la memoria, con un retraso de un par de años, arriesgándose incluso a que le quitaran la mención de becario de la institución por el retraso. Es poco después cuando se publica su conocido artículo en la Revista Nacional de Arquitectura, por lo que se puede aventurar que el mismo pudiera formar parte de la memoria (Figura 6).

En este artículo, titulado "El vidrio y la arquitectura", se van haciendo referencias todo el rato al viaje: "en Pittsburgh seguimos a un curso de estudiantes proyectar una casa total y absolutamente de cristal", "como tampoco fueron utopías aquel primer incomprendido pabellón de Barcelona (sobre el que afanosamente vi trabajar a todo un curso de estudiantes de Arquitectura en Michigan en 1948)", o "la Corning Glass Works de Nueva York, funde al año más de 300 tipos de vidrios diferentes" (Sáenz de Oíza, 1952).

Este artículo se engloba dentro de un monográfico de la Revista Nacional de Arquitectura dedicado al vidrio. Está acompañado por artículos de Carlos de Miguel, Enrique Lantero y tres revisiones de proyectos en los que se ha utilizado el vidrio. Es cierto que, a la vez que alude a ejemplos estadounidenses, también aparecen fotografías de diversas ciudades de Europa, por lo que el interrogante queda abierto, al no haber podido acceder por el momento a la memoria entregada a la Real Academia de Bellas Artes.

Algunos de los arquitectos nombrados al comienzo de este artículo propagaron por España sus viajes, dando a conocer una nueva arquitectura, a través de revistas divulgativas, especializadas o libros. Muchos de ellos se habían traído colecciones de fotografías, extraídas de

\begin{tabular}{|l|}
\hline BARRIOS DE LA FEDERAL HOUSING ADMINISTRATION EN NY: \\
\hline Castell Village \\
Brownville Houses \\
East Riverside Houses \\
Fort Greene Houses \\
James Weldon Thompson Houses \\
John Lovejoit Elliot Houses \\
Stuyvesant Town \\
Parkchester Houses \\
Vladeck City Houses \\
Edificios de la Tennessee Valley Association
\end{tabular}

Tabla 2: Relación de barrios de Nueva York que Sáenz de Oíza recorrió visitando vivienda de la Housing Authority Fuente: Elaboración propia 

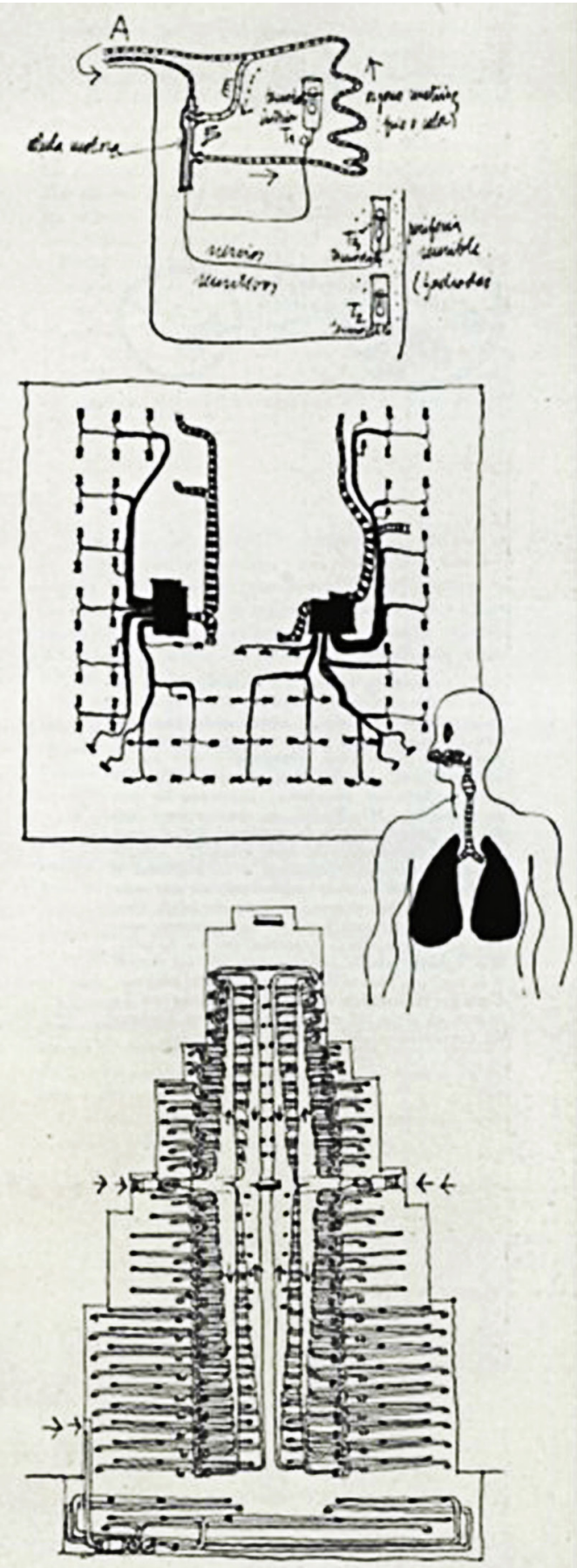

19

Figura 6: Dibujo de las instalaciones de un edificio, realizado y publicado por Sáenz de Oíza

Fuente: Revista Nacional de Arquitectura, no 129, 1952

libros, compradas allí o que habían realizado con sus propias cámaras. De esta manera, ilustraron la narrativa de sus impresiones de los Estados Unidos, añadiendo a sus palabras la fuerza de una imagen. Fueron muy impactantes en su momento las imágenes que aportaban los artículos publicados por Antonio Cámara en la revista Reconstrucción en 1948, por Gabriel Alomar en Cuadernos de Arquitectura en 1950, por Fernando
Chueca Goitia en la Revista Nacional de Arquitectura en 1953, por Miguel Fisac en 1955 en La Actualidad Española o por el grupo liderado por Eugenio Aguinaga, artículo publicado en la Revista Nacional de Arquitectura en 1957.

Se desconoce la autoría de las imágenes que utiliza Sáenz de Oíza en el artículo del que hemos hablado, si fueron suyas o si las adquirió en su viaje o a través de revistas. En ningún momento de la memoria menciona que tuviera una cámara fotográfica, pero sí que adquirió innumerables libros. En cualquier caso, las fotografías contribuyen notablemente a ilustrar lo mencionado en el texto. Como las anteriores, fueron creando un imaginario colectivo en la cabeza de los arquitectos y de la sociedad española, que fue familiarizándose con la arquitectura moderna venida de Estados Unidos.

\section{La huella de un viaje}

Hay aspectos de la docencia de Francisco Javier Sáenz de Oíza que no podrían haberse desarrollado sin su paso por los Estados Unidos, como fue su pasión por las instalaciones, su capacidad de resolución de problemas, su espíritu inquisitivo, etc. Le abrió los ojos a un mundo de abundancia en el que se trabajaba de otra manera:

Me sobrecogió la cultura técnica americana y me cambió muchos de los supuestos de los que yo partía, por ejemplo, que la economía de la construcción era la economía de materiales y descubrí que no, que los alemanes se entretenían en determinar las formas estrictas de una zapata de hormigón para gastar menos material y la cultura americana se basaba en poner más material si con ello salía más barato (Sáenz de Oíza, 2006, p. 17)

No quiso, como otros, aprovecharse del aprendizaje de métodos educativos innovadores, del espíritu crítico que reinaba en el ambiente docente norteamericano, ya que no asistió de manera regular a clases, pero sí que volvió con un espíritu crítico forjado por la experiencia personal, por haberse enfrentado de una manera totalmente novedosa a sus propios planteamientos:

Yo, hombre de formación humanística y artística, fundamentalmente, me encuentro allí con el esplendor del hecho técnico que arrasaba con todos mis supuestos anteriores, y la aclimatación fue un shock tremendo (Sáenz de Oíza, 2006, p. 17)

Ese mismo espíritu crítico e investigador le llevó a patentar varios inventos, desde un aparato de dibujo técnico que mejoraba las posibilidades del paraléx a una tipología de teja. El primero fue anterior a su viaje, en el último año de carrera, y el segundo en los años 60 (Sarasola, 2018). Esto demuestra cómo este arquitecto no se quedaba indiferente ante las necesidades, ante los problemas, sino que se cuestionaba el porqué de las cosas y, al descubrir un problema, utilizaba su inventiva para ponerle solución. Esta actitud interior de cuestionamiento y de búsqueda de soluciones es absolutamente necesaria para aprovechar cualquier viaje, cualquier nueva experiencia con fruto, sacándole el máximo rendimiento. Como dicen Añón y Torres, al analizar la obra de Ciudad Blanca:

[Saénz de Oíza] guarda en su memoria referencias americanas como la obra de Wright, entre otros, que supondrán la iniciación de Oíza en la técnica, en los materiales o en la prefabricación, inquietudes que mantendrá vigentes a lo largo de su carrera (Añón y Torres, 2015, p. 54). 
Es esa pasión por la técnica, no solo traducida en los materiales, sino también en las instalaciones, la que también manifiesta el mismo arquitecto en una sesión de crítica, organizada por Carlos de Miguel y celebrada al poco de su vuelta de los Estados Unidos, en 1951:

Uno de los mayores avances de la arquitectura actual es precisamente esta compleja red de servicios mecánicos e instalaciones que la complementan. Casi nos atreveríamos a decir que le dan vida. Suponed un edificio verdaderamente moderno donde fallen las instalaciones. Se hunde. Muere (Vivanco Bergamín et al., 1951, p. 48).

Si hablamos de su trayectoria posterior y de la huella que dejó en su obra construida, no podemos dejar de mencionar las influencias americanas que vemos en algunas de sus obras, como el organicismo de Frank Lloyd Wright en Torres Blancas o en la casa Lucas Prieto, la influencia de Mies van de Rohe en la casa Durana o los reflejos de los rascacielos americanos en el BBVA, aunque nos quedaríamos en referencias más bien formales.

Sería más destacable el punto de inflexión que supuso en su trayectoria la pregunta por el cómo, por lo que hace que las cosas funcionen, su afición por la tecnología y por entender los sistemas que componen un edificio, que como hemos explicado, se reflejó en su docencia como profesor de la Escuela de Arquitectura.

\section{Conclusiones}

Durante los últimos años se ha llegado a banalizar el hecho de viajar, siendo algo tan habitual que se ha perdido su valor. La gran cantidad de imágenes que recibimos hacen perder la novedad de los sitios que visitamos. Parece que los viajes, incluso los de los estudiantes de arquitectura, se han reducido a una colección de fotografías. En esta última temporada, en la que se viene prolongando la situación de pandemia mundial, hemos perdido la libertad de viajar por el mundo entero como se venía haciendo normalmente. Los intercambios, incluso las clases presenciales, han pasado a ser online, por lo que el disfrute personal de nuevas experiencias ha quedado condicionado a circunstancias sanitarias.

Creemos que es un buen momento para volver a plantearnos el viaje como lo hizo Francisco Javier Sáenz de Oíza, que estando en los Estados Unidos dedicó siete de los nueve meses de su estancia a formarse, a estudiar, a analizar, a preparar lo que luego sería un viaje sin descanso, pero plenamente aprovechado y planificado. Tenemos una oportunidad delante de crecer y que, dentro de lo que esperamos sea poco tiempo, podamos volver a recorrer el mundo con unos ojos muchos más preparados, mucho más observadores, dotando de nuevo a nuestros viajes de un enorme contenido.

Además de las ya enumeradas, podemos extraer de este viaje numerosas enseñanzas para cada uno de nuestros viajes: de los que realizan los profesionales de la arquitectura en la actualidad. El viaje de Sáenz de Oíza estuvo marcado por algunas ideas destacables: la importancia de centrarse en un tema de estudio; no simplemente dejar que las cosas hablen, sino ir a buscarlas y a formarse en un aspecto. Resalta la importancia de los contactos, de aprovechar las oportunidades que van surgiendo. Asimismo, desarrolla una visión crítica de lo visitado, de lo analizado; no simplemente coleccionando imágenes, sino plasmándolas en una memoria, en una carta, en una serie de notas en las que hagan que lo externo pase a ser interno, a través de la valoración, de la emisión de una opinión argumentada sobre un tema concreto. También vemos en su narración que no es necesario mucho dinero para poder moverse, sino saber qué es prescindible y qué no, y guardar los medios para el momento oportuno. Podemos destacar también su interés por todo, por lo grande, por lo pequeño, por lo mediano, abarcando lo que se pueda, pero abiertos a cualquier aspecto novedoso. Esto se consigue siendo personas con una enorme inquietud cultural, con ansias de saber y de conocer, de formarse una opinión propia.

Acabamos con una cita del arquitecto, en la sesión de crítica ya citada, resumiendo su viaje y reforzando esta idea que mencionamos:

Yo he visto, por ejemplo, muchas veces los alzados de Instituto Tecnológico, de Chicago (Mies Van Ver Rohe), antes de visitarlo. No me decían nada; se me aparecían como una retícula más o menos proporcionada (bastante más que menos), muy propia para un edificio fabril o industrial no para un centro universitario. Pero, amigos..., id a verlo... Veréis el juego tan magnífico y el partido sacado a unos pocos elementos: acero desnudo en la estructura, tersas y pulidas lunas de cristal en los huecos, al fondo, cortinajes de vivos colores, persianas venecianas y plantas; en el suelo, a nuestros pies, y envolviéndolo todo, una amplia cortina de césped, y delante unas ligeras y gráciles siluetas de árboles... Acero negro, terso cristal, brillante aluminio... Y ahora, amigos, lo que se me aparecía como un simple edificio fabril, a la vista de los planos, se me presenta en el terreno como una de las construcciones. más claras y bellas del mundo ... Es el juego limpio de unos limpios y nuevos materiales (Vivanzo Bergamín et al., 1951, p. 47).

Cómo citar este artículo/How to cite this article: Salazar Lozano, M., Rodríguez Rodríguez, P. y García Requejo, Z. (2022). Los comienzos de un arquitecto. Crónica del viaje de Sáenz de Oíza por Estados Unidos y México. Estoa. Revista de la Facultad de Arquitectura y Urbanismo de la Universidad de Cuenca, 11 (21), 91-101. https://doi.org/10.18537/est.v011. n021.a08 


\section{Referencias bibliográficas}

Alberdi, R. y Sáenz Guerra, J. (1996). Francisco Javier Sáenz de Oíza. Pronaos.

Añón-Abajas, R. Mạ. y Torres-Dorado, S. (2015). Ciudad Blanca en Bahía de Alcudia. Una obra con sentido pedagógico del profesor Francisco Javier Sáenz de Oíza. Proyecto, Progreso, Arquitectura, (12), 52-71.

Buckley, C. y Rhee, P. (Ed.). (2011). Architect's journey: building, travelling, thinking. GSAPP Books.

Bustos Juez, C. (2015). Pedro Muguruza Otaño (18931952). Aproximación histórica a su obra arquitectónica [Tesis doctoral, Universidad Politécnica de Madrid].

Fernández Balbuena, R. (1922). Los rascacielos norteamericanos. Arquitectura, (34), 41-64.

García-Gutiérrez Mosteiro, J. (1993). Los distintos usos del dibujo de arquitectura de Luis Moya. Revista Academia, Boletín de la Real Academia de Bellas Artes de San Fernando, (77), 246-294.

Martín Gómez, C. (2006). El viaje de Sáenz de Oíza a Estados Unidos (1947-1948). La Arquitectura norteamericana, motor y espejo de la arquitectura española en el arranque de la modernidad (1940-1965), (pp. 151-166). T6 Ediciones

Moreno Villa, J. (1927a). Cartas de Nueva York. El Sol.

Moreno Villa, J. (1927b). Retales de Nueva York. El Sol.

Pozo, J. M. y García-Diego, H. (Ed.). (2010). Viajes en la transición de la arquitectura española hacia la modernidad. T6 Ediciones.

Sáenz de Oíza, F. J. (1952). El vidrio y la arquitectura. Revista Nacional de Arquitectura, (129-130), 25-30.

Sáenz de Oíza, F. J. (1993). La arquitectura: hablando con, F.J. Sáenz de Oiza. Acento

Sáenz de Oíza, F. J. (2006). Escritos y conversaciones / Francisco Javier Sáenz de Oíza. Fundación Caja de Arquitectos.

Sáenz de Oíza, F. J. (1948). Cartas no publicadas de Francisco Javier Sáenz de Oíza al Sr. Secretario de la Real Academia de Bellas Artes de San Fernando. Real Academia de Bellas Artes de San Fernando.

Sarasola Rubio, F. (2018). Sáenz de Oíza, inventor. Las patentes inéditas del arquitecto. Rita, (10), 80-87.

Vivanco Bergamín, L. F. et al. (1951). Funcionalismo y ladrillismo. Revista Nacional de Arquitectura, (119), 3448. 